\title{
A CASE OF "HOLE" AT MACULA DUE TO LOOKING AT THE SUN
}

\author{
BY \\ C. A. PittaR, I.O.M.S. \\ SURGEON LIEUTENANT-COMMANDER, R.N.Z.N.V.R.
}

A.M., Seaman, aged 26 years.-This man was first seen by me at a Royal Naval Hospital on March 11, 1941, complaining of very defective vision of $\mathrm{R}$.E. since June, 1940 .

Examination: V.R. 2/60, V.L. 6/6.

R.E.-Small corneal nebula just below centre of cornea which was not sufficient to affect appreciably visual acuity. Media were otherwise clear. There was a hole at macula with typical punchèdout appearance, otherwise fundus was normal.

There was an absolute central scotoma of a diameter of about $4^{\circ}$.

Peripheral field was full.

L.E.-Normal and healthy.

Refraction under a cycloplegic showed 1 dioptre of hypermetropia in each eye.

History.-This man was first sent to another R.N. Hospital on July 1,1940 , from his ship, a destroyer, with the following history from his medical officer : $\because$. . complains of almost complete blindness in R.E.-duration 3 weeks. Probably due to looking at the sun; ? macular change."

The following notes were made on his bed ticket at hospital :July 1, 1940.-V.R. 2/60, V.L. 6/6, J.1.

R.E.-(1) There is clouding of the macula and pigmentary disturbance. (2) There is a small nebula in centre of the cornea.

July 5, 1940.-Definite hazy cloud at macula-? due to small central corneal nebula.

He was then transferred to a R.N.A.H. where treatment was continued for a corneal ulcer of R.E. No further mention was made of the condition of his fundus except that on July 22, 1940, after recommending his return to duty, vision was noted as $\mathbf{R}$. $<6 / 60$, L. $6 / 5$, with a note: "R.E.- small central corneal nebula. Eye quiet and rest of media clear. Fundi and discs normal.".

\section{Discussion of History}

This is the case of a young man who had normal vision-he was an A.A. gunner, a rate which requires normal vision in each eye which is determined at a special examination by a naval ophthalmic specialist. Then apparently quite suddenly he complained of defective vision in his R.E.

On questioning he stated that enemy planes had a habit of flying out of the sun and that on several occasions he had looked at the 
sun. However there is no clear history of one specific occasion following which the visual defect occurred. The history has also been confused by the fact that about this time he developed a right corneal ulcer. Patient stated that while on deck a spark from the funnel blew into his eye.

There is no history of any blow. on the eye at any time.

At the time his reduced visual acuity was first recorded there were definite, though not well marked, macular changes. Observation was made more difficult by the presence of a central corneal nebula, as is shown by the note on July 5,1940 , when the observer considered the possibility of the cloudy macula area being only an appearance due to looking through a hazy central cornea. Then again 17 days later another observer did not note any abnormality in the fundus.

It would seem that he had an'oedematous condition of the macula shortly after the injury with very slight pigmentary changes. This was apparent three weeks after the onset of symptoms. Three weeks later, i.e., 6 weeks after onset of symptoms, this oedema had probably considerably subsided as there was no macular change noted. However, I consider it most likely that there were changes present at that time which may have been obscured by the corneal nebula. Eight months later he had a typical " hole" at the macula. Central vision in the eye became grossly affected from the start and has shown little or no change since, although the 'fundal picture has altered markedly.

\section{General Discussion}

This case is of interest because it demonstrates a typical hole at the macula as a sequel to a "burn" of the central retina from looking at the sun.

Although it has been stated that a macular hole may occur in eclipse blindness and after exposüre to bright light (Duke-Elder, Text-book of Ophthalmology) this must be considered a rare cause. Indeed I have been unable to find in the literature the report of any case of typical retinal hole at the macula due to exposure to sunlight.

Würdemann in 1936 described a case following exposure to electric welding but this was a much more severe burn accompanied by haemorrhage at the macula and followed by a hole which apparently also involved the choroid so that the sclera showed through. This is a different clinical picture from the ordinary retinal hole with deep red base (choroid) of which my case is an example.

Harman and MacDonald in 1922 reported a case of detachment of the upper half of the retina following the watching of an 
eclipse of the sun. Some macular changes were observed when the detachment had somewhat subsided with rest. However a definite hole at the macula is not described as having been seen, although it may have been a likely assumption to explain the origin of the detachment.

Rauh in 1927 reported a case of central retinal changes following exposure to excessive light and strong heat. This was apparently a localised small central detachment of the retina. There is no suggestion however of a hole in the retina; and the fact that visual acuity in this eye, with a convex lens to compensate for the pushing forward of the macula, was $5 / 6$, and later $5 / 9$, is evidence against such a possibility.

Finally this case seems of especial interest because it demonstrates serious injury to the sight that is likely to occur in modern warfare if adequate precautions are not observed.

\section{REFERENCES}

DUKE-ELDER.-Text-book of Ophthalmology, Vol, III, p. 2757.

Harman and MacDonald.-Brit. Med. Jl., Vol. I, p. 637, 1922.

RUAH.-Zeitschr.f. Augenheilk., Vol. LXIII, p. 48, 1927.

WÜRDEMAN .-Amer. Jl. of Ophthal., Vol. XIX, p. 457, 1936.

\section{ANNOTATION}

\section{"Up to Onè's Eyes"}

Our heading was.suggested to us some time ago by the versatile gentleman who prepares the annual index for the journal. He was up to his eyes in work other than indexing, as he looks upon the latter as pure amusement. Most of us at some time or other have been up to our eyes in work. One calls to mind one's early experiences in the out-patient room at Moorfields. Now that we have retired from practice we spend much of our time up to our eyes in work in the garden, broken once or twice a month by being in a similar condition with regard to proof reading. The simile is an appropriate one for an ophthalmic surgeon and we will leave the the upper limit of the back teeth to our dental colleagues. May all our readers be up to their eyes in work is the best wish we can offer for the first number of a new volume. At the same we may perhaps be pardoned for emphasizing the fact that after more than three years of world war we are still in a position to maintain publication. When one thinks of the enormous upset of national life involved, together with the almost complete cessation of our exchange journal copies save those of the Empire and the United States, it seems a marvel that we have kept afloat. We are deeply in the debt of those who, 